\title{
High-Field (3.4T) ENDOR Investigation of Asphaltenes in Native Oil and Vanadyl Complexes by Asphaltene Adsorption on Alumina Surface
}

\author{
Marat Gafurov (D), ${ }^{1}$ Georgy Mamin, ${ }^{1}$ Irina Gracheva, ${ }^{1}$ Fadis Murzakhanov, ${ }^{1}$ Yulia Ganeeva, ${ }^{1,2}$ \\ Tatiana Yusupova, ${ }^{1,2}$ and Sergei Orlinskii ${ }^{1}$ \\ ${ }^{1}$ Kazan Federal University, 420008 Kazan, Russia \\ ${ }^{2}$ FRC Kazan Scientific Center of RAS, Arbuzov Institute of Organic and Physical Chemistry, 420088 Kazan, Russia \\ Correspondence should be addressed to Marat Gafurov; marat.gafurov@kpfu.ru
}

Received 23 October 2018; Accepted 12 February 2019; Published 16 May 2019

Academic Editor: Mohammad Sarmadivaleh

Copyright (C) 2019 Marat Gafurov et al. This is an open access article distributed under the Creative Commons Attribution License, which permits unrestricted use, distribution, and reproduction in any medium, provided the original work is properly cited.

Vanadyl porphyrin complexes in asphaltenes from heavy (Karmalinskoye) oil and in asphaltene films obtained as a result of adsorption on the surface of aluminum oxide were studied by electron paramagnetic resonance (EPR) and double electronnuclear resonance (ENDOR) in the W-band frequency range (microwave frequency of $95 \mathrm{GHz}$, magnetic field of $3.4 \mathrm{~T}$ ). Mims ENDOR spectra from ${ }^{1} \mathrm{H}$ and ${ }^{27} \mathrm{Al}$ nuclei are observed. ENDOR spectra are different for native oil and asphaltenes from one side and the adsorbed samples from the other side while no significant changes in X- (microwave frequency of $9 \mathrm{GHz}$ ) or W-band EPR spectra are found. The results allow supposing that vanadyl porphyrin complexes (at least in the studied asphaltene films) participate in the formation of asphaltene aggregates through the functional groups rather than $\pi$ $-\pi$ interactions. The data show the feasibility of the commercial pulsed ENDOR approaches for the investigation of crude oils and their constituents under external influence.

\section{Introduction}

The rising economic significance of heavy crude oils demands the application of different analytical tools for their characterization in situ and corresponding theoretical studies of interactions between the different oil constituents. Heavy petroleum and natural bitumen includes several metallic chemical forms. Among them, vanadium and nickel are a common cause of catalyst degradation and deactivation in hydrotreatment units. For the effective extraction of the metals, the molecular structure of the metal complexes and their location (binding) in the asphaltene-resin aggregates are intensively studied [1-6]. These studies appear even more interesting in light of the data proposing vanadyl complexes as a part of quantum computers $[7,8]$ and even as a sensitive probe in biomedical applications [9].

Among the efficient ways of removal of asphaltenes and metal complexes from oils and studying their structure, the adsorption (deposition) of the oils and their structural units on the surface of different supports is widely used and is a matter of intensive studies [10-15]. Besides the rapid removing of asphaltenes from the heavy oil making therefore the remaining fraction of oil transportable for conventional processing, the mentioned supports (especially in the form of nanoparticles) could be employed as catalysts for upgrading asphaltenes into light usable distillates [10]. Alumina$\left(\mathrm{Al}_{2} \mathrm{O}_{3}\right)$ based materials are one of the favorable choices for these purposes due to the high adsorption capacity.

The majority of vanadium and nickel compounds are present in heavy petroleum as porphyrins and concentrated in asphaltenes. In general, petroleum porphyrins exist in homologous manifolds of several structural classes and can manifest great structural diversity. A series of papers nowadays is devoted to the determination of various vanadyl porphyrins (VP), to application of state-of-the-art massspectroscopic techniques for that purpose as well as to the development of different pathways of the effective vanadyl extraction $[1,4,16-23]$. Dickie and Yen were the first to 
suggest that, having many of the same interactive groups as asphaltenes, petroporphyrins could also play a role in asphaltene self-assembly, adsorption, and phase separation [24]. It is common knowledge that intermolecular interactions, such as hydrogen bonding, dipole-dipole interactions, and $\pi-\pi$ stacking, in asphaltenes lead to aggregation into nanoaggregates in the bulk oil phase and the formation of elastic films at organic-aqueous interfaces although the basic asphaltene structure and mechanism of aggregation continue to be debated $[2,17,25]$. The relationship between petroporphyrins and asphaltenes is largely unexplored [1, 4, 26-28].

Since practically all petroleum systems, especially highmolecular oil components (asphaltenes and resins) are paramagnetic [29-32], the presence of intrinsic paramagnetic centers (PC), primarily paramagnetic vanadyl-porphyrin complexes and organic "free" radicals (FR), gives an opportunity to study the structure (organization) of petroleum complexes without additional processing, in situ [2]. Different aspects of application of various electron paramagnetic resonance (EPR) and double resonance (ENDOR) techniques for the elucidation of the asphaltene architecture and the oil PC nature are covered in refs. [2, 19, 32-46].

The effectiveness of the use of the VP as a native probe for the investigation of asphaltenes is determined by the resolved anisotropic spectral parameters ( $g$-factor and hyperfine components, zero-field splitting, quadrupole tensors) in the EPR/ENDOR spectra, which makes VP to be orientationselective even in disordered media [40-51]. Using X-band (microwave frequency $v_{\mathrm{MW}}$ of $9 \mathrm{GHz}$, magnetic field $B_{0}$ of $0.34 \mathrm{~T})$ and high-frequency $\left(v_{\mathrm{MW}}\right.$ of $95 \mathrm{GHz}, \mathrm{B}_{0}$ of $3.4 \mathrm{~T}$, $\mathrm{W}$-band) conventional and pulsed EPR/ENDOR techniques, we have shown that, on the one hand, the EPR and ENDOR spectra for VP in the initial oil samples of different genesis are similar while, on other hand, the relaxation parameters of VP (the electron longitudinal $\left(T_{1 \mathrm{e}}\right)$ and transverse $\left(T_{2 \mathrm{e}}\right)$ relaxation times) and the temperature dependences of the EPR spectra depend strongly on the nature of the sample and the method of the fractionation procedure [49-52]. It was also shown that changes in the VP EPR spectra could be used to track the oxidation processes under the influence of manganese [53]. In this paper, we investigate changes in EPR/ENDOR spectra during the adsorption of asphaltenes onto aluminum oxide particles by using an experience of EPR/ENDOR alumina characterization described in previous papers of our group $[54,55]$.

\section{Materials and Methods}

Samples of heavy oil from the Karmalinskoye oilfield (VolgaUral Basin, Republic of Tatarstan, Russia) with a density $\rho=948 \mathrm{~kg} / \mathrm{m}^{3}$ and a viscosity $\eta=580 \mathrm{mPa}$ 's at room temperature were used to obtain samples of asphaltenes (As) in the form of a powder. Compositional analysis of the oil sample (SARA analysis) was conducted according to the common technique [56] which includes asphaltene precipitation by heptane and further chromatographic separation of the asphaltene free oil through a column filled with alumina. SARA (saturate, aromatic, resin, and asphaltene) analysis data of the studied crude oil are presented
TABLE 1: Results of SARA analysis for the crude oil sample.

\begin{tabular}{lccc}
\hline & \multicolumn{2}{c}{ SARA } & analysis (\%) \\
Saturate & Aromatic & Resin & Asphaltene \\
\hline 18.4 & 44.8 & 28.4 & 8.4 \\
\hline
\end{tabular}

in Table 1. Organic solvents, such as toluene, heptane, dichloromethane, and methanol (purity of all solvents was no less than 99.5\%), were purchased from ComponentReaktiv and used without additional purification. Aluminum oxide $\left(\gamma-\mathrm{Al}_{2} \mathrm{O}_{3}\right.$, particle size $0.05-0.15 \mathrm{~mm}$, neutral, surface area $155 \mathrm{~m}^{2} / \mathrm{g}$ ) were purchased from Sigma-Aldrich (CAS 1334-28-1). Data on NMR investigation for the oil under study are presented in ref [57].

To prepare asphaltene films, $1.000 \mathrm{~g}$ of $\mathrm{Al}_{2} \mathrm{O}_{3}$ was added to dichloromethane solutions containing $2 \times 10^{-3} \mathrm{~g} \times \mathrm{ml}^{-1}$ (sample Q10) or $2 \times 10^{-2} \mathrm{~g} \times \mathrm{ml}^{-1}$ (sample Q1) of As in round-bottom flasks. The chosen concentration values were determined by the solubility of As (sample with the high As concentration-Q1) and the sensitivity of the EPR spectrometer (sample with the low As concentration-Q10). Obtained mixtures were shacked for $30 \mathrm{~min}$, and then $\mathrm{Al}_{2} \mathrm{O}_{3}$ with adsorbed asphaltenes was filtered off and dried in a vacuum evaporator $\left(20 \mathrm{mbar}, 40^{\circ} \mathrm{C}\right)$.

W-band EPR spectra at $T=100 \mathrm{~K}$ were registered with a Bruker ElexSys 680 EPR spectrometer by using standard electron spin echo (ESE) $\pi / 2-\tau-\pi$ with the $\pi / 2$ pulse duration of $32 \mathrm{~ns}$, time delay $\tau=240 \mathrm{~ns}$ pulse sequence. The ability to detect ESE gives an opportunity to obtain ENDOR spectra by using Mims pulse sequence $\pi / 2-\tau-\pi / 2-T-\pi / 2$ with an additional radiofrequency (RF) pulse $\pi_{\mathrm{RF}}=18 \mu \mathrm{s}$ (the pulse length is optimized for ${ }^{1} \mathrm{H}$ nuclei) inserted between the second and third microwave $\pi / 2$ pulses (Figure 1 ). RF frequency in our setup could be swept in the range of (1-200) MHz. More details of the pulsed W-band EPR and ENDOR measurements for oils and polymers with the corresponding references are given in our papers [50, 58].

X-band $(9 \mathrm{GHz})$ EPR and concentration measurements were performed at room temperature by comparing the integrated intensities of the spectra of a test sample and a reference sample (DPPH and a series of Cu-DETC solutions) in conventional $(\mathrm{cW})$ mode. Spectral simulations are done in EasySpin package for MatLab [59]. Some of the experimental results were presented at the international Workshop "Thermal methods for enhanced oil recovery” ThEOR-2017 [60].

\section{Results and Discussion}

EPR spectra detected at the X-band (Figure 2) for oil, oil components (resins and asphaltenes), and adsorbed asphaltenes are very similar to each other and are defined by the presence of stable "free" radical (FR, single line, electron spin $S=1 / 2, g \approx 2.003)$ and paramagnetic vanadyl complexes (VP) while the initial $\mathrm{Al}_{2} \mathrm{O}_{3}$ samples are EPR silent within the sensitivity limit of our instruments. Origin and EPR of FR (especially at the conventional X-band) in oils and oil asphaltenes are comprehensively described in the literature 


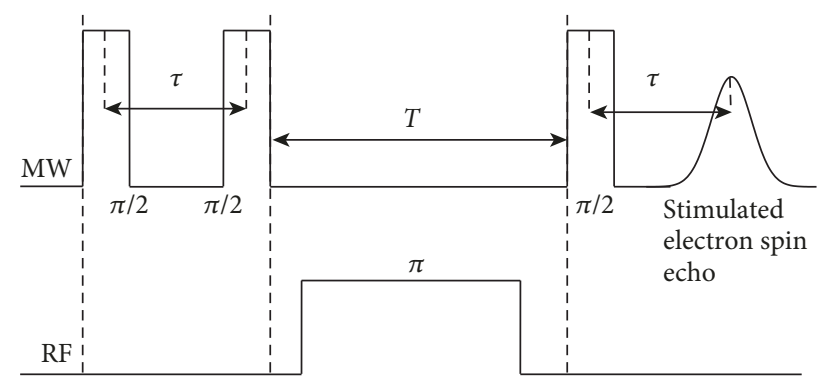

FIGURE 1: Mims pulse sequence at microwave and radiofrequencies used to obtain the ENDOR spectra as a function of the stimulated electron spin echo amplitude from the frequency of RF pulse. The values of time delays $(\tau, T)$ and pulse lengths $(\pi / 2$ for MW and $\pi$ for $\mathrm{RF}$ ) are given in the text.

(see [46] and references therein) and are not in the scope of the present study.

Assuming a nearly planar skeleton structure of a single VP molecule $\left(\mathrm{VO}^{2+}, S=1 / 2\right.$, Figure 3 ), the EPR spectra could be satisfactory described by the $g$-tensor of axial symmetry with $g_{\|} \approx 1.96, g_{\perp} \approx 1.98$, and anisotropic hyperfine interaction with a magnetic moment $I=7 / 2$ (therefore, 8 projections of $I$ with the quantum numbers $\mathrm{m}_{I}= \pm 7 / 2 ; \pm 5 / 2 ; \pm 3 / 2$ and $\pm 1 / 2$ are possible) for ${ }^{51} \mathrm{~V}$ nuclei (natural abundance of 99.75\%) with hyperfine structure constants $A_{\|} \approx 480 \mathrm{MHz}$, $A_{\perp} \approx 157 \mathrm{MHz}$ (Table 2). In our notations, the values of $(g, A)_{\|}$correspond to the orientation perpendicular to the $\mathrm{VO}^{2+}$ plane (out of plane), and along the direction $c$ and $(g, A) \perp$ correspond to the orientation in the $\mathrm{VO}^{2+}$ plane, $a b$ plane (see Figure 3). As for the most $\mathrm{VO}^{2+}$-related investigations, we suppose that the direction of the main axes coincide for $g$ and $A$ tensors. Comprehensive description of VP spectra in the X-band, their spectral simulations, and spectral changes with external treatment are given in $[49,52]$. For instance, a fitting of the asphaltene EPR spectrum is shown in Figure 2. Results of the concentration measurements for the investigated powders are presented in Table 3.

As it follows from Table 3, concentrations of both FR and $\mathrm{VP}$ of $\mathrm{As} / \mathrm{Al}_{2} \mathrm{O}_{3}$ samples decrease with the lowering of the As amount that could serve as additional proof of the proper (proportional to the As quantity) precipitation and sample refining. The concentration of VP relative to FR also reduces. It could be assumed that asphaltenes with a more condensed structure and lower VP content are adsorbed on alumina. It agrees with the previously revealed trend of inverse dependence of the concentration of FR on the content of vanadyl complexes (see papers $[19,21,22]$ and references therein). Alternatively (or additionally), a formation/disappearing of new stable radicals, in which EPR spectra are indistinguishable from the initial ones, as a result, for example, of chemical bond opening/chemical bonding and oxidation processes upon adsorption $[60,61]$, could be supposed.

W-band EPR spectra in ESE mode at $T=100 \mathrm{~K}$ (at room temperatures, the electronic relaxation times are too short to obtain ESE and ENDOR with the appropriate signal-to-noise ratio) are presented in Figure 4. Due to the difference in values of $g$ factors, $\mathrm{W}$-band experiments allow separating
FR and VP contributions spectrally. Data for the components of $g$ and $A$ tensors for VP extracted from the simulations of $\mathrm{VP}$ spectra in the $\mathrm{W}$-band are presented in Table 2 . In details, the nature and simulations of the $\mathrm{W}$-band spectra are discussed in refs. $[45,50,51]$. For clarity, Figure 5 presents the calculated electronic-nuclear energy levels of the $\mathrm{VO}^{2+}$ paramagnetic complex, EPR transitions, and the corresponding EPR absorption line with the values of the components of $g$ and $A$ close to those obtained in the experiment.

As it is seen from Figures 1 and 4 and Table 2, no significant changes of EPR spectra either in the X- or W-band occur with asphaltene extraction or deposition (except for some broadening of the lines in the spectrum for samples Q1 and Q10). It is often assumed that such kind of treatment should result in changes of the observed $g$ values $[62,63]$. In this case, the so-called B parameter has been widely used as a sensitive indicator of structural distortions in the $\mathrm{V}=\mathrm{O}$ bond length which can be derived as follows:

$$
B=\Delta g_{\|} / \Delta g_{\perp}
$$

where $\Delta g_{\|}=g_{\|}-g_{\mathrm{e}}, \Delta g_{\perp}=g_{\perp}-g_{\mathrm{e}}$, and $g_{\mathrm{e}}$ is the free electron $g$ value of 2.0023 .

For example, an increase in the $B$ parameter is conventionally ascribed to a shorter $\mathrm{V}=\mathrm{O}$ bond and/or a longer distance to the nitrogen ligands, i.e., the higher electron density in the axial bond and more electron delocalization to the $V$ orbital. Absence of the $g$ component shift or significant changes of the $A$ components in our study mean that no significant redistribution of the electronic density for VP single molecules occurs with the extraction or adsorption.

The same conclusion could be derived from the comparison of the oil and asphaltene ${ }^{1} \mathrm{H}$ ENDOR spectra (Figure 6): the ${ }^{1} \mathrm{H}$ ENDOR pattern (splittings along the ENDOR spectrum) for the asphaltene sample is the same as that for the initial oil. The obtained ENDOR is different for the parallel and perpendicular orientations, are in the range of 0.32.4 MHz, and could be ascribed to the interaction with the protons of the following structures of vanadyl porphyrins identified in natural hydrocarbons: etioporphyrin (VOEtio), deoxophylloerythroetioporphyrin (VODPEP), and benzoetioporphyrin (VOBenzo, see [50]).

In the case of a "free" nucleus, RF pulse applied at the Larmor frequency is

$$
v_{\text {Larmor }}=\left|\gamma \mathrm{B}_{0}\right| \equiv h^{-1}\left|\mathrm{~g}^{(\mathrm{I})} \beta^{(\mathrm{I})} \mathrm{B}_{0}\right|
$$

where $\gamma$ is a gyromagnetic ratio of the nuclear spin $I, h$ is a Planck constant, $g^{(I)}$ is a nuclear $g$ factor and $\beta^{(I)}$ is a nuclear Bohr magneton, which can change the state of the nuclear spin (the population of the nuclear sublevels). For proton with $I=1 / 2, \gamma_{1 \mathrm{H}}=42.576 \mathrm{MHz} / \mathrm{T}$ that results in $\nu_{\text {Larmor }} \approx$ 144.76 MHz for the magnetic field of $B_{0}=3.4 \mathrm{~T}$.

In the case of a coupled electron spin $S$ and a single nuclear spin, such changing can modify the state of the electron spin (can change the population of the energy levels contributing to the EPR spectrum). For the hyperfine 


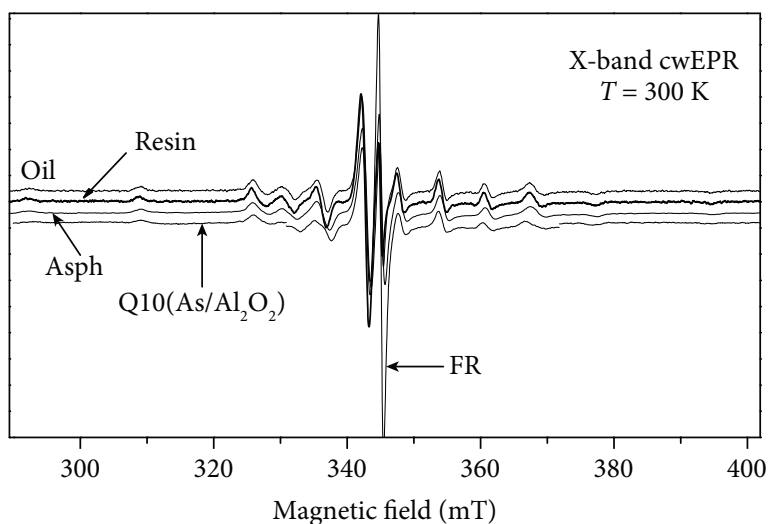

(a)

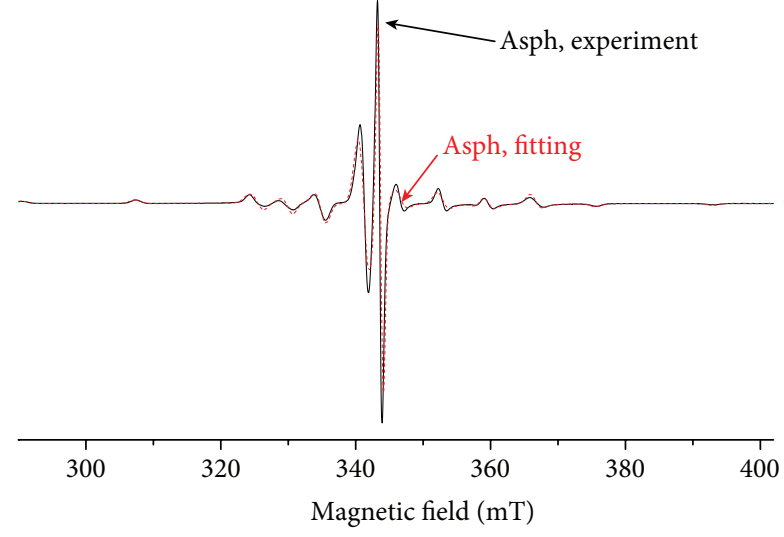

(b)

FIGURE 2: (a) conventional X-band EPR spectra of oil, resins, and asphaltenes and deposited on alumina surface asphaltenes (sample Q10) at room temperature. The signal belonging to FR is marked. Other EPR components originate from VP complexes. (b) example of the experimental (black solid line) asphaltene EPR spectrum fitting (red dashed line) in the EasySpin package for MatLab [59] with the parameters given in Table 2.
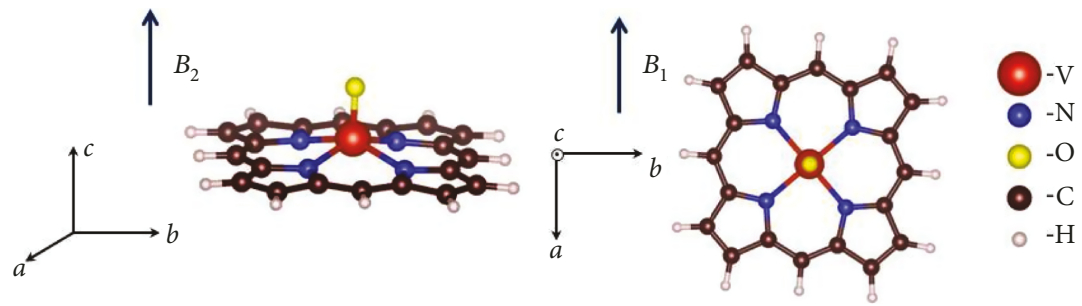

FIGURE 3: Schematic representation of a single vanadyl porphyrin molecule. The directions of the external magnetic fields "in-plane" $\left(B_{2}\right)$ and "out-of-plane" $\left(B_{1}\right)$ for the W-band ENDOR measurements are shown (see Figures 4 and 5).

TABLE 2: EPR parameters for vanadyls derived from the MATLAB EasySpin approximations [59] of EPR spectra for two frequency ranges. Details of approximations are given in [49-52].

\begin{tabular}{lcccccccc}
\hline & & \multicolumn{3}{c}{ X-band } & & \multicolumn{2}{c}{ W-band } \\
& $g_{\|}$ & $g_{\perp}$ & $A_{\|}(\mathrm{MHz})$ & $A_{\perp}(\mathrm{MHz})$ & $g_{\|}$ & $g_{\perp}$ & $A_{\|}(\mathrm{MHz})$ & $A_{\perp}(\mathrm{MHz})$ \\
\hline Oil & 1.965 & 1.986 & 480 & 157 & 1.961 & 1.982 & 482 \\
Asphaltenes & 1.9644 & 1.986 & 480 & 157 & 1.961 & 1.9825 & 475 \\
Q1, Q10 & 1.965 & 1.986 & 475 & 157 & 1.963 & 1.9818 & 460 & 157 \\
\hline
\end{tabular}

TABLE 3: Concentrations (C) of FR and VP in asphaltenes and the adsorbed samples from the X-band measurements.

\begin{tabular}{lccc}
\hline Sample & $C(\mathrm{VP})$, spin/g & $C(\mathrm{FR}), \mathrm{spin} / \mathrm{g}$ & $C(\mathrm{VP}) / C(\mathrm{FR})$ \\
\hline Asphaltenes & $1.4 \cdot 10^{19}$ & $1.4 \cdot 10^{18}$ & 10.0 \\
Q1 & $4 \cdot 10^{17}$ & $8 \cdot 10^{16}$ & 5.0 \\
Q10 & $1 \cdot 10^{17}$ & $2.6 \cdot 10^{16}$ & 3.8 \\
\hline
\end{tabular}

coupling constant $A$ and simple electron-nuclear coupling $(S=1 / 2, I=1 / 2)$, it can lead to the appearance of the characteristic features in the ENDOR spectrum at the RF frequencies. or

$$
v_{\mathrm{ENDOR}}=A / 2 \pm v_{\text {Larmor }},
$$

depending on the ratio between $A$ and $\nu_{\text {Larmor }}$. In the case of more than one nucleus coupled with electron spin, one can observe the multiple signals around the corresponding Larmor frequencies or $A / 2$ with different hyperfine coupling constants or $v_{\text {Larmor }}$.

In [50], the ${ }^{1} \mathrm{H}$ ENDOR spectra of the oil under study were comprehensively investigated and the experimental results were compared with the density functional theory (DFT) calculations. The obtained ENDOR splittings, according to DFT, correspond to the interatomic distances between the vanadium ion and the closest protons in the range of $0.46-0.6 \mathrm{~nm}$ for the nearly plane geometry of the single VP molecules mentioned above (see Figure 3). 


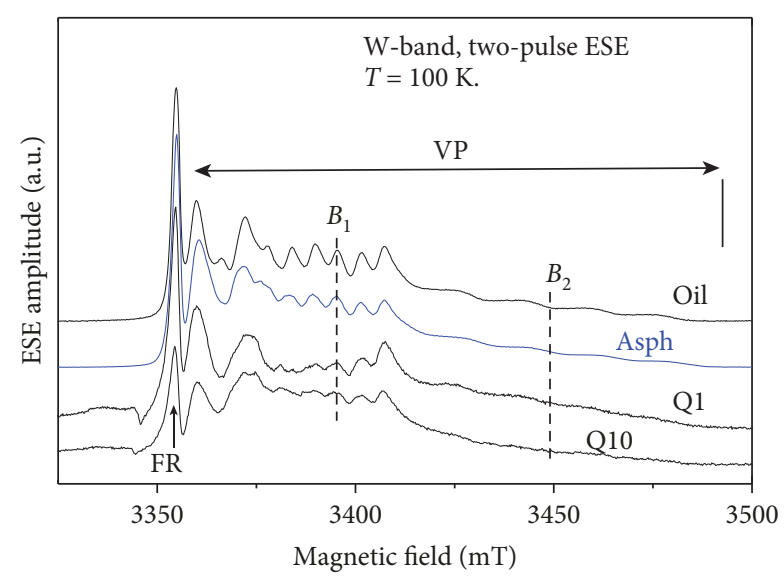

FIGURE 4: W-band spectra of the investigated samples in ESE mode at $T=100 \mathrm{~K}$. Position of FR line and VP spectra are marked by arrows. Values of the magnetic fields $B_{1}$ and $B_{2}$ in which ${ }^{1} \mathrm{H}$ ENDOR spectra were registered are shown.

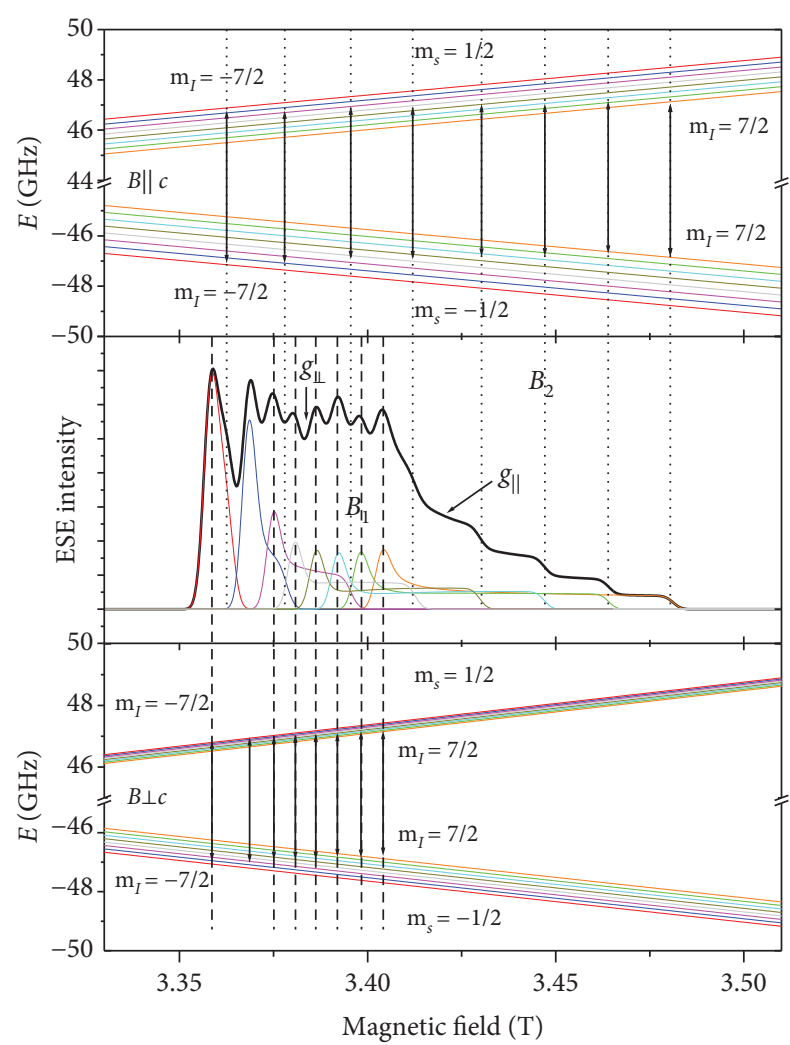

FIgURE 5: The energy levels (the top panel for the magnetic field directed along "out-of-plane" while the bottom one for the magnetic field "in-plane," see Figure 3) and the corresponding absorption EPR spectrum (central panel) for $\mathrm{VO}^{2+}$ complex calculated for the microwave frequency $v=94 \mathrm{GHz}, g_{\|}=1.96, g_{\perp}=$ 1.98, $A_{\|}=470 \mathrm{MHz}$, and $A_{\perp}=150 \mathrm{MHz}$. Particular contributions from every EPR transition are color-marked. Calculations are done in EasySpin package for MatLab [59] in the assumption that the main axes of $g$ and $A$ tensors coincide. The arrows mark the values of the magnetic field equivalent to the values of $g_{\|}$and $g_{\perp}$. The values of external magnetic field that correspond to the EPR transitions with $\mathrm{mI}=+3 / 2$ are denoted as $B_{1}$ and $B_{2}$.

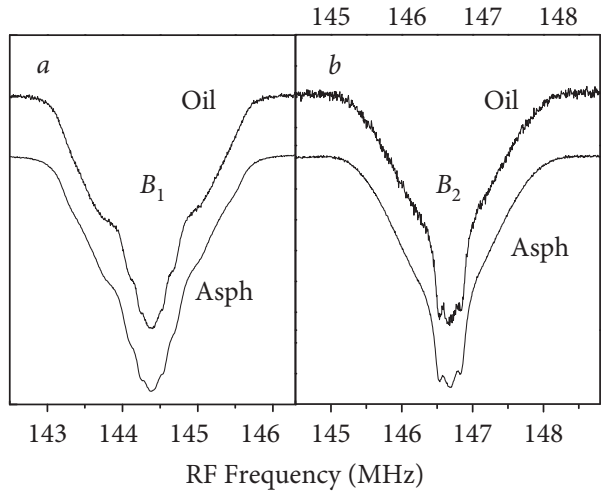

FIgURE 6: Mims ENDOR for the initial oil and asphaltenes near the proton Larmor frequency measured at (a) $B_{1}=3395.3 \mathrm{mT}$ and (b) $B_{2}=3448.9 \mathrm{mT}$. $T=20 \mathrm{~K}, \mathrm{~W}$-band.

In ref. [50], the choice of the external magnetic fields denoted as $B_{1}$ and $B_{2}$, correspondingly, in which the ENDOR spectra were acquired, was explained in details. Briefly, for convenience such values of $B_{0}$ were chosen that correspond to "pure" parallel and perpendicular orientations of the external magnetic field relative to VP geometry: the $B_{1}$ value corresponds to $B_{0}$ "in-plane," perpendicular to the $c$-axis, while $B_{2}$ for those "out-of-plane" for $\mathrm{m}_{I}=3 / 2$ transitions (Figures 3 and 5). Besides being from the same $\mathrm{m}_{I}$ (that simplifies the interpretation and theoretical analyses), the next reasons were outlined in ref. [50]: (1) the sufficient ESE amplitudes to obtain a reasonable signal-to-noise ratio for the appropriate time for both values/orientations, (2) absence of overlapping with the shoulders of the FR signal, and (3) absence of the orthogonal contributions.

Comparison of the proton ENDOR for asphaltenes and the adsorbed samples Q1 and Q10 are shown in Figure 7. A significant difference in the central part of the spectra of the proton ENDOR with adsorption is obtained. For convenience, the difference ${ }^{1} \mathrm{H}$ ENDOR spectra (results of the subtraction of the asphaltene ENDOR spectrum from the Q1 and Q10 ENDOR spectra, correspondingly) are presented in Figure 8.

The narrow ENDOR peak symmetrically centered on the ${ }^{1} \mathrm{H}$ Larmor frequency (see Figure 8) has a linewidth on the half weight of $\Delta f=(0.16 \pm 0.02) \mathrm{MHz}$. It is due to the hyperfine interaction of VP with a large number of the remote protons. In assumption of the simple electron-proton point-dipole approximation which is applicable for the large distances between electron and nuclear spins, one can estimate the electron-proton distance $r$

$$
|\Delta f|=\frac{g_{S} g_{I} \beta_{S} \beta_{I}\left(3 \cos ^{2} \Theta-1\right)}{r^{3}}
$$

where $g_{S}, g_{I}, \beta_{S}$, and $\beta_{I}$ are the $g$ factors and Bohr's magnetons of the electron and nucleus, respectively, and $\Theta$ is the polar angle between the direction of the applied magnetic field and the line connecting the $S$ and $I$ spins, which can be taken as 0 degree in disordered systems for the minimal 


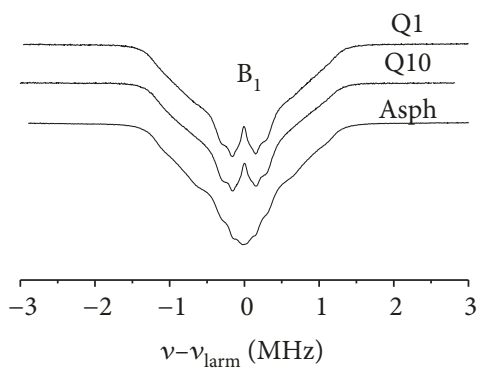

(a)

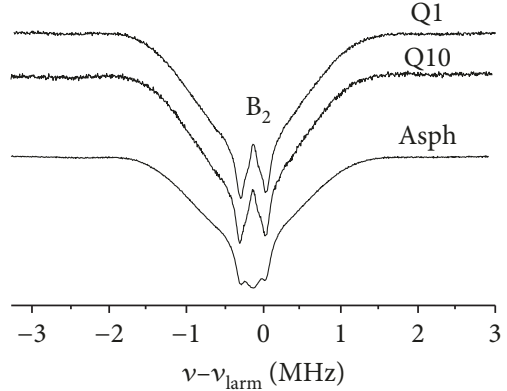

(b)

FIgURE 7: Mims ENDOR near the proton Larmor frequency measured for asphaltenes and adsorbed samples Q1 and Q10 at (a) $B_{1}=$ $3395.3 \mathrm{mT}$ and (b) $B_{2}=3448.9 \mathrm{mT}$. T $=20 \mathrm{~K}, \mathrm{~W}$-band.

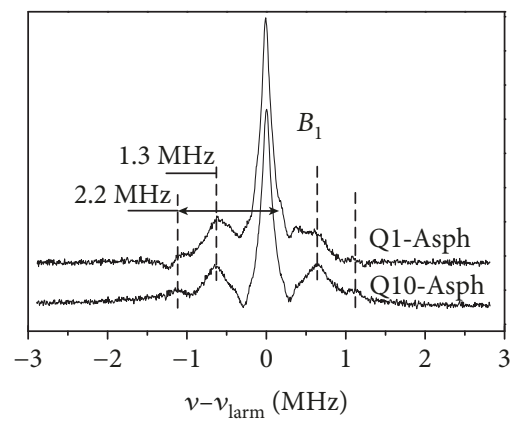

(a)

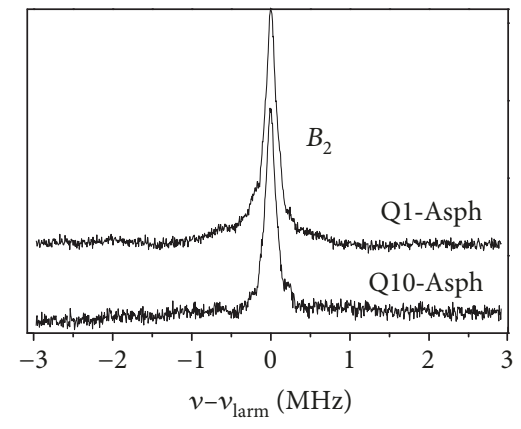

(b)

Figure 8: ${ }^{1} \mathrm{H}$ difference ENDOR spectra for samples Q1 and Q10 measured at (a) $B_{1}=3395.3 \mathrm{mT}$ and (b) $B_{2}=3448.9 \mathrm{mT}$.

distance estimation. The obtained value of $\Delta f$ corresponds to remote nuclei, e.g., to a distance of $\sim 0.8 \mathrm{~nm}$ and larger between the paramagnetic centers and the protons, and is observed for both (parallel and perpendicular) orientations.

The presence of the resolved, orientation-dependent (but concentration-independent) ENDOR structure allows suggesting that the association of most of the paramagnetic vanadyl porphyrins in the asphaltenes (or at least in the asphaltene films) of the oil studied is due to the interaction through the functional groups attached to the porphyrin ring. Indeed, while only the central peak disappears in ENDOR at the "out-of-plane" magnetic field $B_{0}=B_{2}$ (Figures 7(b) and 8(b)), in the magnetic "in-plane" field $B_{1}$ one can additionally observe that ENDOR lines with the splittings of 1.3 and $2.2 \mathrm{MHz}$, correspondingly, are coming out during the asphaltene adsorption (Figure 8(a)). In our opinion, it means that the asphaltene adsorption leads not only to the detaching of the remote protons (at the distance of larger than $0.8 \mathrm{~nm}$, isotropic interaction) but also to the breaking of some hydrogen bonds in the porphyrin plane (anisotropic interaction) with the electron-proton distance in the range of $0.4-0.6 \mathrm{~nm}$ [50]. In the case of $\pi-\pi$ interaction, it could be expected that one would observe some concentration-dependent changes in ${ }^{1} \mathrm{H}$ ENDOR spectra with adsorption and mainly (or additionally) at $B_{0}=B_{2}$.

Dickie and Yen were the first who proposed an aggregation scheme for the macrostructure of petroleum asphaltenes, within which petroporphyrins could stack to the aromatic sheets of asphaltene [24]. Their opinion as well as the abilities of EPR techniques to shed light on aggregation structure was criticized by authors of [64]. In [64], solutions of porphyrin complexes (i.e., model systems) were investigated by UV-Vis and fluorescence spectroscopy. From the lack of detectable binding of these model compounds, it was suggested that the association of the majority of vanadium and nickel petroporphyrins in crude oils with the asphaltene fraction may be due to other functionalities appended to the porphyrin ring, rather than favorable $\pi-\pi$ stacking interactions of aromatic rings with the porphyrin core itself. Our ENDOR (i.e., EPRbased) positive experimental results (i.e., based not on the failure of detection but on success of detection) carried out on real (i.e., not model) oil samples are in correspondence with the title and conclusions of ref. [64].

For the adsorbed samples, we also have observed ${ }^{27} \mathrm{Al}$ Mims ENDOR spectra. Figure 9 shows for the Q10 sample at $T=10 \mathrm{~K}$ at the magnetic field $B_{1}$ which corresponds to the maximal ESE signal (see Figure 4) to enhance the signal-to-noise ratio. Aluminum ENDOR shows that potroporhyrins in the studied species are indeed adsorbed on the alumina surface, forming the electron-nuclear complexes. In this sense, ENDOR could be fruitfully utilized for studying adsorption of oil constituents by substances containing the species with the nuclear spins like alumina and silica [65]. From the other side, the value of ENDOR splitting of 


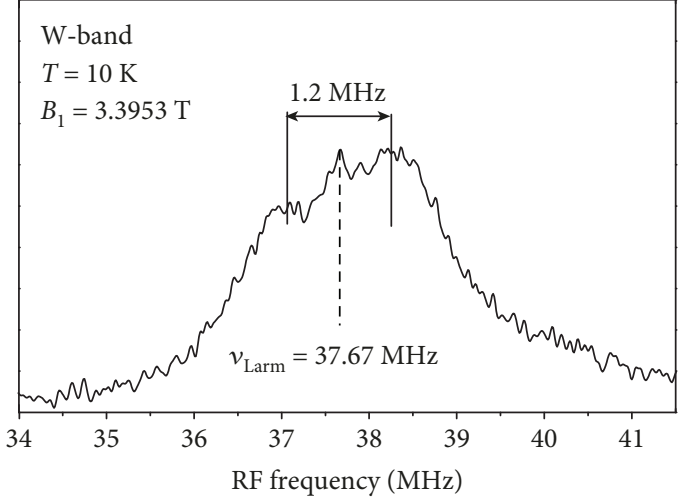

Figure 9: ${ }^{27} \mathrm{Al}$ ENDOR spectra for sample Q10 measured at $B_{1}=$ $3395.3 \mathrm{mT}$.

1.2 $\mathrm{MHz}(\sim 0.045 \mathrm{mT})$ gives an additional sign that no significant redistribution of the electronic density occurred during the asphaltene precipitation. It means that the presented approach allows determining VP complex formation without other presumption or sophisticated calculations. It also gives a key why the observed by ${ }^{1} \mathrm{H}$ ENDOR changes are practically not revealed by EPR - the changes are minimal and are hidden under the broadening of the EPR lines either in $\mathrm{X}$ - or W-band ranges.

We did not manage to obtain ${ }^{27} \mathrm{Al}$ Mims ENDOR for $B_{0}=B_{2}$. It might be connected with just the lower signal-tonoise ratio in the EPR spectrum compared to $B_{1}$ (Figures 4 and 5), and therefore, no deep conclusions from that fact are done in this work.

\section{Conclusion}

While the EPR spectra either in X- or W-band do not reveal the changes caused by adsorption of oil asphaltenes on the surface of $\gamma$-alumina, a perceptible difference in ${ }^{1} \mathrm{H}$ ENDOR spectra and appearance of ${ }^{27} \mathrm{Al}$ ENDOR spectra are obtained. High-frequency EPR/ENDOR allows resolving the anisotropy of the magnetic properties of stable vanadyl complexes being a part of asphaltenes and, therefore, is orientationselective for the space structure of VP complexes. From the analysis of ${ }^{1} \mathrm{H}$ ENDOR spectra, it could be supposed that vanadyl porphyrin complexes participate in the formation of asphaltene aggregates (at least in the studied films) through the functional groups rather than $\pi-\pi$ interactions. It appears that application of double resonance techniques, especially at high frequencies (high magnetic fields), could significantly improve the understanding of the mechanisms of the aggregation (complex formation, self-organization) of various oil constituents and other high-molecular disordered systems of biogenic and synthetic origins $[66,67]$.

\section{Data Availability}

The data used in this study are available from the corresponding author on reasonable request.

\section{Disclosure}

Experimental results were presented in parts at the international workshops "Thermal methods for enhanced oil recovery" ThEOR-2017 [60] and ThEOR-2018 (Kazan Russia and Chengdu, China, correspondingly) and at Arbuzov memorial conference "Dynamic processes in the chemistry of organoelement compounds - 2018” (Kazan, Russia) [68].

\section{Conflicts of Interest}

The authors declare that there is no conflict of interest regarding the publication of this paper.

\section{Acknowledgments}

The work is supported by the Program of the competitive growth of Kazan Federal University (“5-100"). S. Orlinskii acknowledges a financial support of the Russian Science Foundation, grant \# 18-13-00149, for the possibility to carry out high-field ENDOR measurements on nanosized systems. The authors are thankful to Andrey Galukhin for providing the oil and adsorbed samples, and Centre of the Shared Facilities of Kazan Federal University are acknowledged for the possibility to use their equipment. Scientific Committees of the mentioned Events are also acknowledged.

\section{References}

[1] B. M. Rytting, I. D. Singh, P. K. Kilpatrick, M. R. Harper, A. S. Mennito, and Y. Zhang, "Ultrahigh-purity vanadyl petroporphyrins," Energy \& Fuels, vol. 32, no. 5, pp. 5711-5724, 2018.

[2] O. N. Martyanov, Y. V. Larichev, E. V. Morozov, S. N. Trukhan, and S. G. Kazarian, "The stability and evolution of oil systems studiedviaadvanced methodsin situ," Russian Chemical Reviews, vol. 86, no. 11, pp. 999-1023, 2017.

[3] J. I. Park, I. Mochida, A. M. Marafi, and A. Al-Mutairi, "Modern approaches to hydrotreating catalysis," in Springer Handbook of Petroleum Technology, C. S. Hsu and P. R. Robinson, Eds., vol. 21, pp. 675-712, Springer, 2017.

[4] X. Zhao, C. Xu, and Q. Shi, "Porphyrins in heavy petroleums: a review," Structure and Bonding, vol. 168, pp. 39-70, 2015.

[5] T. A. Maryutina and A. R. Timerbaev, "Metal speciation analysis of petroleum: myth or reality?," Analytica Chimica Acta, vol. 991, pp. 1-8, 2017.

[6] T. A. Maryutina, O. N. Katasonova, E. Y. Savonina, and B. Y. Spivakov, "Present-day methods for the determination of trace elements in oil and its fractions," Journal of Analytical Chemistry, vol. 72, no. 5, pp. 490-509, 2017.

[7] L. Tesi, E. Lucaccini, I. Cimatti et al., Chemical Science, vol. 7, no. 3, pp. 2074-2083, 2016.

[8] M. Atzori, L. Tesi, E. Morra, M. Chiesa, L. Sorace, and R. Sessoli, American Chemical Society, vol. 138, no. 7, pp. 2154-2157, 2016.

[9] S. A. Dikanov, B. D. Liboiron, and C. Orvig, "VO ${ }^{2+}$-hydroxyapatite complexes as models for vanadyl coordination to phosphate in bone," Molecular Physics, vol. 111, no. 18-19, pp. 2967-2979, 2013.

[10] N. L. Ezeonyeka, A. Hemmati-Sarapardeh, and M. M. Husein, "Asphaltenes adsorption onto metal oxide nanoparticles: a 
critical evaluation of measurement techniques," Energy \& Fuels, vol. 32, no. 2, pp. 2213-2223, 2018.

[11] M. L. Chacón-Patiño, S. M. Rowland, and R. P. Rodgers, "Advances in asphaltene petroleomics. Part 2: selective separation method that reveals fractions enriched in island and archipelago structural motifs by mass spectrometry," Energy \& Fuels, vol. 32, no. 1, pp. 314-328, 2017.

[12] V. Gonzalez and S. E. Taylor, "Asphaltene adsorption on quartz sand in the presence of pre-adsorbed water," Journal of Colloid and Interface Science, vol. 480, pp. 137-145, 2016.

[13] N. N. Nassar, "Asphaltene adsorption onto alumina nanoparticles: kinetics and thermodynamic studies," Energy \& Fuels, vol. 24, no. 8, pp. 4116-4122, 2010.

[14] J. Saint-Just, "Catalyst characterization by adsorption of petroleum asphaltenes in solution," Industrial \& Engineering Chemistry Product Research and Development, vol. 19, no. 1, pp. 71-75, 1980.

[15] D. Zhang, T. Wen, Y. Xiong, D. Qiu, and Q. Wen, "Effect of $\mathrm{Al}_{2} \mathrm{O}_{3}$ buffer layers on the properties of sputtered $\mathrm{VO}_{2}$ thin films," Nano-Micro Letters, vol. 9, no. 3, p. 29, 2017.

[16] D. F. Smith, D. C. Podgorski, R. P. Rodgers, G. T. Blakney, and C. L. Hendrickson, "21 tesla FT-ICR mass spectrometer for ultrahigh-resolution analysis of complex organic mixtures," Analytical Chemistry, vol. 90, no. 3, pp. 2041-2047, 2018.

[17] C. Ovalles and M. E. Moir, The Boduszynski Continuum: Contributions to the Understanding of the Molecular Composition of Petroleum, ACS Symposium Series; OUP, Washington, USA, 2018.

[18] D. Giraldo-Dávila, M. L. Chacón-Patiño, J. S. Ramirez-Pradilla, C. Blanco-Tirado, and M. Y. Combariza, "Selective ionization by electron-transfer MALDI-MS of vanadyl porphyrins from crude oils," Fuel, vol. 226, pp. 103-111, 2018.

[19] M. R. Yakubov, D. V. Milordov, S. G. Yakubova et al., "Vanadium and paramagnetic vanadyl complexes content in asphaltenes of heavy oils of various productive sediments," Petroleum Science and Technology, vol. 35, no. 14, pp. 1468-1472, 2017.

[20] C. X. Yin, J. M. Stryker, and M. R. Gray, "Separation of petroporphyrins from asphaltenes by chemical modification and selective affinity chromatography," Energy \& Fuels, vol. 23, no. 5, pp. 2600-2605, 2009.

[21] N. A. Mironov, G. R. Abilova, K. O. Sinyashin et al., "Chromatographic isolation of petroleum Vanadyl porphyrins using sulfocationites as sorbents," Energy \& Fuels, vol. 32, no. 1, pp. 161-168, 2017.

[22] M. R. Yakubov, D. V. Milordov, S. G. Yakubova et al., "Features of the composition of vanadyl porphyrins in the crude extract of asphaltenes of heavy oil with high vanadium content," Petroleum Science and Technology, vol. 34, no. 2, pp. 177-183, 2016.

[23] J. C. Putman, S. M. Rowland, Y. E. Corilo, and A. M. McKenna, "Chromatographic enrichment and subsequent separation of nickel and vanadyl porphyrins from natural seeps and molecular characterization by positive electrospray ionization FT-ICR mass spectrometry," Analytical Chemistry, vol. 86, no. 21, pp. 10708-10715, 2014.

[24] J. P. Dickie and T. F. Yen, "Macrostructures of the asphaltic fractions by various instrumental methods," Analytical Chemistry, vol. 39, no. 14, pp. 1847-1852, 1967.

[25] Y. M. Ganeeva, T. N. Yusupova, and G. V. Romanov, “Asphaltene nano-aggregates: structure, phase transitions and effect on petroleum systems," Russian Chemical Reviews, vol. 80, no. 10, pp. 993-1008, 2011.

[26] H. S. Silva, A. C. R. Sodero, J.-P. Korb et al., "The role of metalloporphyrins on the physical-chemical properties of petroleum fluids," Fuel, vol. 188, pp. 374-381, 2017.

[27] Y. Y. Borisova, E. G. Tazeeva, N. A. Mironov et al., "Role of vanadylporphyrins in the flocculation and sedimentation of asphaltenes of heavy oils with high vanadium content," Energy \& Fuels, vol. 31, no. 12, pp. 13382-13391, 2017.

[28] G. P. Dechaine and M. R. Gray, "Chemistry and association of vanadium compounds in heavy oil and bitumen, and implications for their selective removal," Energy \& Fuels, vol. 24, no. 5, pp. 2795-2808, 2010.

[29] N. S. Garif ianov and B. M. Kozyrev, "Paramagnetic resonance in anthracite and other carbon-containing materials," Journal of Experimental and Theoretical Physics, vol. 3, pp. 255-258, 1956.

[30] H. S. Gutowsky, B. Roger Ray, R. L. Rutledge, and R. R. J. Unterberger, "Carbonaceous free radicals in crude petroleum," Chemical Physics, vol. 28, pp. 744-745, 1958.

[31] D. E. J. O'Reilly, "Paramagnetic resonance of vanadyl etioporphyrin I," Chemical Physics, vol. 29, pp. 1188-1189, 1958.

[32] T. Yen and G. Chilingarian, Eds., Asphaltenes and Asphalts 1, New York, Elsevier, 1994.

[33] N. M. Khasanova, D. T. Gabdrakhmanov, G. P. Kayukova, F. N. Mikhaylova, and V. P. Morozov, "Magnetic resonance in solids," Electronic Journal, vol. 19, pp. 1-11, 2017.

[34] G. K. Wong and T. F. Yen, “An electron spin resonance probe method for the understanding of petroleum asphaltene macrostructure," Journal of Petroleum Science and Engineering, vol. 28, no. 1-2, pp. 55-64, 2000.

[35] V. E. Galtsev, I. M. Ametov, and O. Y. Grinberg, "Asphaltene association in crude oil as studied by ENDOR," Fuel, vol. 74, no. 5, pp. 670-673, 1995.

[36] A. K. Shukla, Ed., Analytical Characterization Methods for Crude Oil and Related Products, JohnWiley \& Sons ltd, Hooboken, USA, 2018.

[37] S. N. Trukhan, S. G. Kazarian, and O. N. Martyanov, Energy \& Fuels, vol. 31, no. 1, pp. 387-394, 2017.

[38] V. M. Malhotra and H. A. Buckmaster, "34 GHz e.p.r. study of vanadyl complexes in various asphaltenes," Fuel, vol. 64, no. 3, pp. 335-341, 1985.

[39] R. Scotti and L. Montanari, "Molecular structure and intermolecular interaction of asphaltenes by FT-IR, NMR, EPR," in Structures and Dynamics of Asphaltenes, Springer, Boston, MA, 1998.

[40] L. G. Gilinskaya, L. S. Borisova, and E. A. Kostyreva, "Structural modifications of $\mathrm{VO}^{2+}$ chelates in the organic matter of oils and bitumens from the EPR spectra," Journal of Structural Chemistry, vol. 56, no. 3, pp. 436-445, 2015.

[41] L. G. Gilinskaya, "EPR spectra of V(IV) complexes and the structure of oil porphyrins," Journal of Structural Chemistry, vol. 49, no. 2, pp. 245-254, 2008.

[42] K. Ben Tayeb, O. Delpoux, J. Barbier, J. Marques, J. Verstraete, and H. Vezin, "Applications of pulsed electron paramagnetic resonance spectroscopy to the identification of vanadyl complexes in asphaltene molecules. Part 1: influence of the origin of the feed," Energy \& Fuels, vol. 29, no. 7, pp. 4608-4615, 2015.

[43] K. Ben Tayeb, O. Delpoux, J. Barbier, P. Chatron-Michaud, M. Digne, and H. Vezin, "Applications of pulsed electron 
paramagnetic resonance spectroscopy to the identification of vanadyl complexes in asphaltene molecules. Part 2: hydrotreatment monitoring," Energy \& Fuels, vol. 31, no. 3, pp. 3288-3294, 2017.

[44] S. N. Trukhan, V. F. Yudanov, A. A. Gabrienko, V. Subramani, S. G. Kazarian, and O. N. Martyanov, "In situ electron spin resonance study of molecular dynamics of asphaltenes at elevated temperature and pressure," Energy \& Fuels, vol. 28, no. 10, pp. 6315-6321, 2014.

[45] V. Ramachandran, J. van Tol, A. M. McKenna, R. P. Rodgers, A. G. Marshall, and N. S. Dalal, Analytical Chemistry, vol. 87, no. 4, pp. 2306-2313, 2015.

[46] B. Gizatullin, M. Gafurov, A. Rodionov et al., "Proton-radical interaction in crude oil-a combined NMR and EPR study," Energy \& Fuels, vol. 32, no. 11, pp. 11261-11268, 2018.

[47] A. S. Alexandrov, R. V. Archipov, A. A. Ivanov, O. I. Gnezdilov, M. R. Gafurov, and V. D. Skirda, "The low-field pulsed mode dynamic nuclear polarization in the pentavalent chromium complex and crude oils," Applied Magnetic Resonance, vol. 45, no. 11, pp. 1275-1287, 2014.

[48] I. N. Gracheva, M. R. Gafurov, G. V. Mamin et al., "ENDOR study of nitrogen hyperfine and quadrupole tensors in vanadyl porphyrins of heavy crude oil," Magnetic Resonance in Solids. Electronic Journal, vol. 18, no. 1, 2016.

[49] M. R. Gafurov, M. A. Volodin, A. A. Rodionov et al., "EPR study of spectra transformations of the intrinsic vanadylporphyrin complexes in heavy crude oils with temperature to probe the asphaltenes' aggregation," Journal of Petroleum Science and Engineering, vol. 166, pp. 363-368, 2018.

[50] T. Biktagirov, M. Gafurov, G. Mamin, I. Gracheva, A. Galukhin, and S. Orlinskii, "In situ identification of various structural features of vanadyl porphyrins in crude oil by highfield (3.4 T) electron-nuclear double resonance spectroscopy combined with density functional theory calculations," Energy \& Fuels, vol. 31, no. 2, pp. 1243-1249, 2017.

[51] G. V. Mamin, M. R. Gafurov, R. V. Yusupov et al., “Toward the asphaltene structure by electron paramagnetic resonance relaxation studies at high fields (3.4 T), Energy \& Fuels, vol. 30, no. 9, pp. 6942-6946, 2016.

[52] T. B. Biktagirov, M. R. Gafurov, M. A. Volodin et al., "Electron paramagnetic resonance study of rotational mobility of vanadyl porphyrin complexes in crude oil asphaltenes: probing the effect of thermal treatment of heavy oils," Energy \& Fuels, vol. 28, no. 10, pp. 6683-6687, 2014.

[53] A. Galukhin, M. A. Khelkhal, A. Gerasimov et al., "Mn-catalyzed oxidation of heavy oil in porous media: kinetics and some aspects of the mechanism," Energy \& Fuels, vol. 30, no. 9, pp. 7731-7737, 2016.

[54] I. N. Mukhambetov, A. A. Lamberov, B. V. Yavkin, M. R. Gafurov, G. V. Mamin, and S. B. Orlinskii, "Electron paramagnetic resonance and electron nuclear double resonance study of the paramagnetic complexes of anthraquinone on the surface of $\gamma$-Al2O3," Journal of Physical Chemistry C, vol. 118, no. 27, pp. 14998-15003, 2014.

[55] M. R. Gafurov, I. N. Mukhambetov, B. V. Yavkin, G. V. Mamin, A. A. Lamberov, and S. B. Orlinskii, "Quantitative analysis of Lewis acid centers of $\gamma$-alumina by using EPR of the adsorbed anthraquinone as a probe molecule: comparison with the pyridine, carbon monoxide IR, and TPD of ammonia," Journal of Physical Chemistry C, vol. 119, no. 49, pp. 27410-27415, 2015.
[56] A. V. Galukhin, A. A. Erokhin, Y. N. Osin, and D. K. Nurgaliev, "Catalytic aquathermolysis of heavy oil with iron tris(acetylacetonate): changes of heavy oil composition and in situ formation of magnetic nanoparticles," Energy \& Fuels, vol. 29, no. 8, pp. 4768-4773, 2015.

[57] I. Z. Rakhmatullin, S. V. Efimov, B. Y. Margulis, and V. V. Klochkov, "Qualitative and quantitative analysis of oil samples extracted from some Bashkortostan and Tatarstan oilfields based on NMR spectroscopy data," Journal of Petroleum Science and Engineering, vol. 156, pp. 12-18, 2017.

[58] A. Konkin, U. Ritter, A. A. Konkin et al., "W-band ENDOR of light-induced PPerAcr anion radicals in double-crystalline donor-bridge-acceptor P3HT-b-PPerAcr block copolymer in frozen solution: experimental and DFT study," Journal of Physical Chemistry C, vol. 122, no. 40, pp. 22829-22837, 2018.

[59] S. Stoll and A. Schweiger, "EasySpin, a comprehensive software package for spectral simulation and analysis in EPR," Journal of Magnetic Resonance, vol. 178, no. 1, pp. 42-55, 2006.

[60] G. Mamin, M. Gafurov, A. Galukhin et al., "W-band EPR of vanadyl complexes aggregates on the surface of $\mathrm{Al}_{2} \mathrm{O}_{3}$," IOP Conference Series: Earth and Environmental Science, vol. 155, article 12005, 2018.

[61] S. S. Mehrabi-Kalajahi, M. A. Varfolomeev, C. Yuan et al., "EPR as a complementary tool for the analysis of lowtemperature oxidation reactions of crude oils," Journal of Petroleum Science and Engineering, vol. 169, pp. 673-682, 2018.

[62] V. K. Sharma, A. Wokaun, and A. Baiker, "ESR characterization of vanadium pentoxide monolayers and double layers supported on various carriers," The Journal of Physical Chemistry, vol. 90, no. 12, pp. 2715-2718, 1986.

[63] Q. Cui, K. Nakabayashi, X. Ma et al., "Examining the molecular entanglement between $\mathrm{V}=\mathrm{O}$ complexes and their matrices in atmospheric residues by ESR," RSC Advances, vol. 7, no. 60, pp. 37908-37914, 2017.

[64] C.-X. Yin, X. Tan, K. Mullen, J. M. Stryker, and M. R. Gray, "Associative $\pi-\pi$ interactions of condensed aromatic compounds with vanadyl or nickel porphyrin complexes are not observed in the organic phase," Energy \& Fuels, vol. 22, no. 4, pp. 2465-2469, 2008.

[65] M. Gafurov, A. Galukhin, Y. Osin et al., "Probing the surface of mesoporous synthetic opals with the vanadyl containing crude oil by using EPR and ENDOR techniques," Magnetic Resonance in Solids, vol. 21, p. 19101, 2019.

[66] B. Gabbasov, M. Gafurov, A. Starshova et al., "Conventional, pulsed and high-field electron paramagnetic resonance for studying metal impurities in calcium phosphates of biogenic and synthetic origins," Journal of Magnetism and Magnetic Materials, vol. 470, pp. 109-117, 2019.

[67] A. Galukhin, D. Bolmatenkov, and Y. Osin, "Heavy oil oxidation in the nano-porous medium of synthetic opal," RSC Advances, vol. 8, no. 32, pp. 18110-18116, 2018.

[68] M. R. Gafurov, I. N. Gracheva, G. V. Mamin, Y. M. Ganeeva, T. N. Yusupova, and S. B. Orlinskii, "Study of organic self-assembled nanosystems by means of highfrequency ESR/ENDOR: the case of oil asphaltenes," Russian Journal of General Chemistry, vol. 88, no. 11, pp. 2374-2380, 2018. 

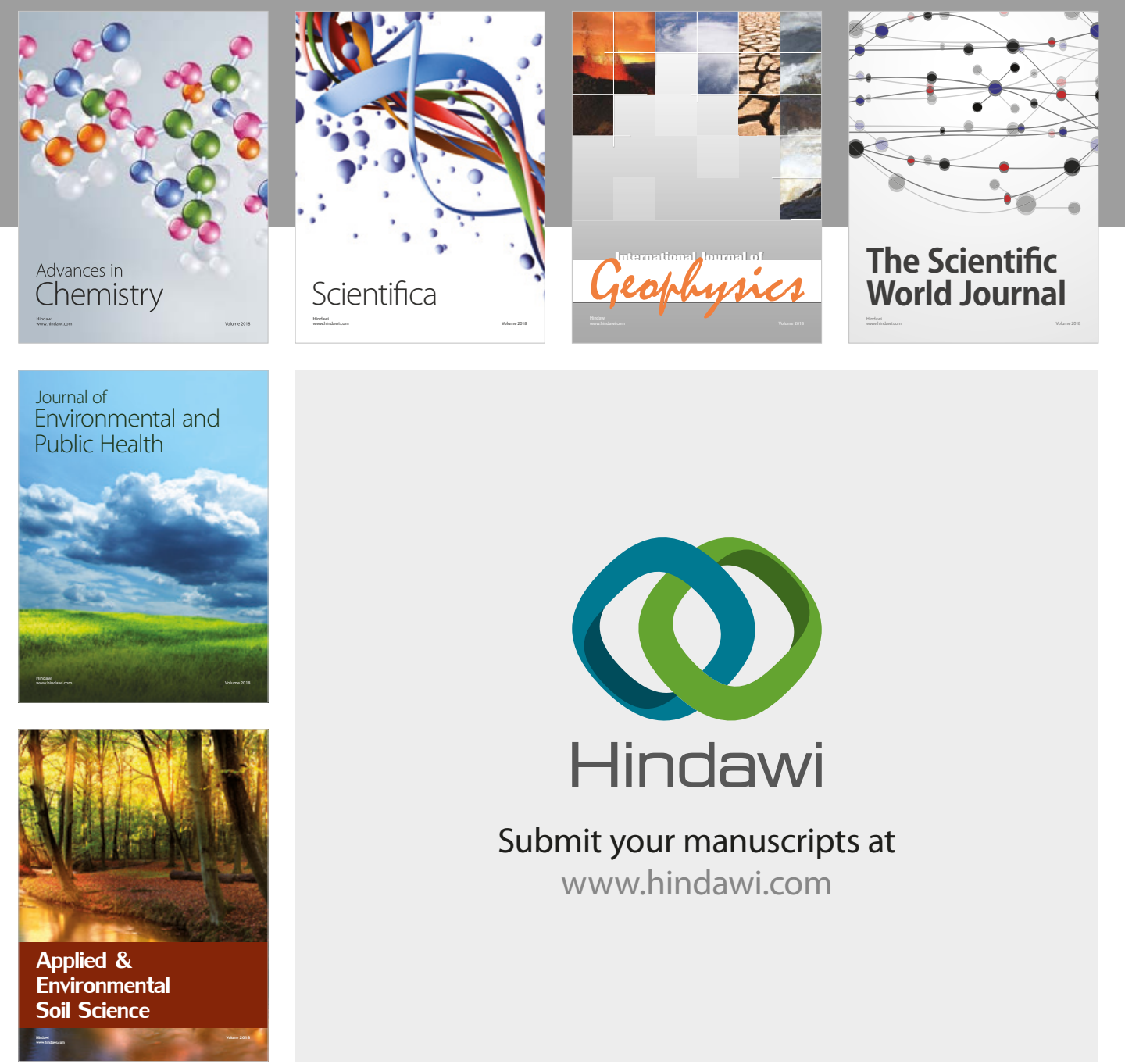

The Scientific

\section{World Journal}
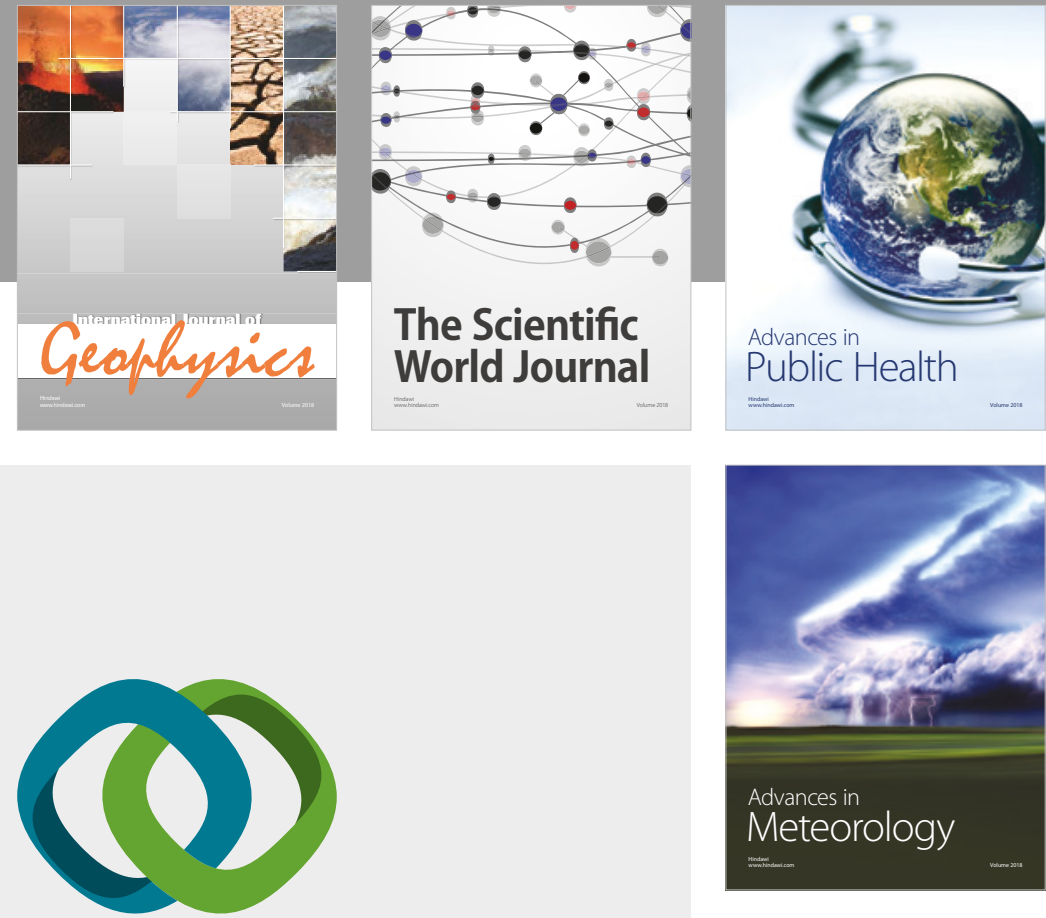

Advan

Public Health

\section{Hindawi}

Submit your manuscripts at

www.hindawi.com
